Post-print version of the following article published in Reproduction, Fertility and Development

\title{
Physiological parameters related to oocyte nuclear differentiation for the improvement of IVM/IVF outcomes in women and cattle
}

Jose Buratini ${ }^{\mathrm{A}, \mathrm{B}, *}$, Ana Caroline Silva Soares $^{\mathrm{B}}$, Rodrigo Garcia Barros ${ }^{\mathrm{C}}$, Thaisy Tino Dellaqua $^{B}$, Valentina Lodde ${ }^{C}$, Federica Franciosi ${ }^{C}$, Mariabeatrice Dal Canto ${ }^{A}$, Mario Mignini Renzini ${ }^{\mathrm{A}}$ and Alberto Maria Luciano ${ }^{\mathrm{C}}$

Affiliations

ABiogenesi Reproductive Medicine Centre - Eugin Group, Istituti Clinici Zucchi, Monza, Italy.

${ }^{B}$ Department of Structural and Functional Biology, Sao Paulo State University, Botucatu, Brazil.

${ }^{\mathrm{C}}$ Reproductive and Developmental Biology Laboratory, Department of Health, Animal Science and Food Safety, University of Milan, Milan, Italy.

Reproduction, Fertility and Development 34(1-2), 27-35. doi:10.1071/RD21278

Published: 8 November 2021

\begin{abstract}
In vitro maturation (IVM) has been applied in numerous different contexts and strategies in humans and animals, but in both cases it represents a challenge still far from being overcome. Despite the large dataset produced over the last two decades on the mechanisms that govern antral follicular development and oocyte metabolism and differentiation, IVM outcomes are still unsatisfactory. This review specifically focuses on data concerning the potential consequences of using supraphysiological levels of FSH during IVM, as well as on the regulation of oocyte chromatin dynamics and its utility as a potential marker of oocyte developmental competence. Taken together, the data revisited herein indicate that a significant improvement in IVM efficacy may be provided by the integration of pre-OPU patientspecific protocols preparing the oocyte population for IVM and more physiological culture systems mimicking more precisely the follicular environment that would be experienced by the recovered oocytes until completion of metaphase II.
\end{abstract}




\section{Introduction}

The developing ovarian follicle provides the optimal environment for oocyte maturation and developmental competence acquisition under physiological regulation (Sirard 2016). In most cases, the application of assisted reproductive technologies (ART) inherently disrupts this environment. The need to increase productivity and sustainability of dairy and beef industries has prompted an increase of the application of in vitro embryo production (IVP) in cattle in the last two decades (Baruselli et al. 2016; Webb and Buratini 2016; Viana 2020). Typically, IVP schemes applied in cattle rely on the use of oocytes aspirated from follicles at different developmental stages preceding ovulation. These oocytes are then exposed to in vitro maturation (IVM), which is followed by in vitro fertilisation (IVF) and embryo culture (IVC) up to the blastocyst stage to generate high numbers of IVP for embryo transfer (ET) to recipients. This sequence of manipulations can be further amplified by cryopreservation and thawing of the embryo, in order to allow storage and shipment, as well as embryo sexing. In vitro maturation (IVM) has been recognised as the major bottleneck in cattle IVP since it was demonstrated to be highly inefficient in comparison with in vivo maturation (Rizos et al. 2002; Sutton et al. 2003; Sirard et al. 2006; Katz-Jaffe et al. 2009; Blanco et al. 2011). Despite the considerable progress of our knowledge on the mechanisms regulating folliculogenesis and oocyte maturation over the last 20 years, IVP outcomes have not been substantially improved during this time window (Luciano and Sirard 2018). Strong evidence indicates that the still low IVP efficiency in cattle derives, at least in part, from the use of a single.

non-physiological IVM system for oocytes collected at various stages of differentiation (Soares et al. 2020a, 2020b). In addition, in order to support the maturation signalling cascade in vitro, most IVM culture media contain FSH at concentrations far higher than those present in the follicular fluid during final follicle growth and at the time of ovulation (Fortune and Hansel 1985), which can potentially impinge on chromatin dynamics, cumulus-oocyte communication and oocyte transcriptional/translational activity, thus reducing oocyte developmental competence (Combelles et al. 2004; Luciano et al. 2011; Chen et al. 2013).

Alternatively, in human reproductive medicine, IVF has been utilised to treat couple infertility using different strategies than those applied in cattle. In human IVF practice, oocyte maturation is usually triggered with hCG or a GnRH agonist at the end of controlled ovarian stimulation (COS) so that MII (metaphase II) oocytes ready to be fertilised are yielded by ovum pick-up (OPU). In such context, IVM has been predominantly applied simply to allow still immature oocytes to reach fertilisation ability after in vivo triggering of the maturation cascade (Fadini et al. 2015), in media deprived of direct regulators of the maturation process such as FSH or EGF/EGF-like factors, commonly used in cattle IVM. In the face of inferior pregnancy and live birth rates achieved with IVM in relation to IVF with oocytes reaching metaphase II in vivo, in women, IVM has been practically restricted to specific patient groups for which conventional COS is contraindicated, particularly those affected by polycystic ovarian syndrome (PCOS) or at risk of developing the ovarian hyperstimulation syndrome (OHSS) (Fadini et al. 2013, 2015; De Vos et al. 2016, 2021). In the absence of a culture system capable to efficiently mimic the intrafollicular environment, IVM has been more often and successfully applied after mild/short ovarian stimulation with 
$\mathrm{FSH}$, followed by in vivo activation of final maturation with hCG in women (Fadini et al. 2009; Dal Canto et al. 2012). Nonetheless, IVM has been also applied to increase IVF outcomes by giving a chance to immature GV (germinal vesicle) and MI oocytes retrieved after regular COS/OPU to reach metaphase II in vitro, a strategy known as 'rescue IVM' (De Vos et al. 2021; Jie et al. 2021). A third IVM modality - considered by experts in the field as true human IVM, since in such case oocyte maturation is indeed triggered in vitro - has been only recently proposed to treat human infertility (Coticchio et al. 2016; De Vos et al. 2016, 2021). Based on original studies in mice revealing the role of the natriuretic peptide $C$ (NPPC) and estradiol in the control of the meiotic arrest (Zhang et al. 2010, 2011), as well as on subsequent reports in cattle indicating the applicability of the NPPC/estradiol combination to improve oocyte developmental competence in IVP practice (Franciosi et al. 2014; Soares et al. 2017), a two-step IVM system has been proposed for women (Sánchez et al. 2017, 2019). Although this system has been proved useful to treat sub-fertile PCOS patients (Vuong et al. 2020), its efficiency must be still improved so that IVM application can be expanded to other patient groups and significantly impact treatment cost and patient comfort/safety in human IVF practice, via reduction of gonadotrophin administration.

Aiming to shed light on the limitations of IVM in both animal and human reproduction and to generate insights for its improvement, herein we revise and articulate the literature indicating that the stage(s) of oocyte differentiation and exposure to adequate FSH signalling are fundamental aspects to be considered and optimised in order to enhance oocyte developmental competence in preparation for IVF. In particular, we revisit studies investigating (1) the conse- quences of supraphysiological FSH signalling during follicle growth or IVM on oocyte homeostasis, as well as (2) the utilisation of chromatin configuration as a parameter to synchronise oocyte differentiation stage before IVM/IVF in order to improve embryo production.

The physiological follicular environment as reference: the importance of cumulusoocyte communication and the impact of supraphysiological FSH

Physiologically, oocyte differentiation progressively occurs in the intrafollicular environment (Sirard 2016; Luciano and Sirard 2018). It has been clearly demonstrated that disruption of this environment can prematurely induce chromatin compaction and transcription silencing, disturbances that have been identified as major causes of developmental competence loss during IVM (Hyttel 1987; Lodde et al. 2007). Data accumulated over the last decade indicate that both of these phenomena are consequences of diminished cumulus-oocyte communication, leading to reduced accumu- lation of small KD signalling molecules and mRNA essential to sustain adequate oocyte metabolism, meiosis completion, DNA integrity, and finally, after fertilisation, early embryo development (J. Buratini, T. T. Dellaqua, M. Dal Canto, A. La Marca, M. Mignini Renzini, R. Webb, unpubl. data).

The interaction between the oocyte and cumulus cells has been extensively revised (Gilchrist 2011; Russell et al. 2016; Buratini et al. 2017; Richani et al. 2021). Apart from paracrine bidirectional regulation, a fundamental part of cumulus-oocyte communication is mediated by transzonal projections (TZP), which are extensions of 
cumulus cells that penetrate the zona pellucida and reach the oocyte to deliver small molecules essential for oocyte homeostasis transported through GAP-junctions, as well as poly A-mRNA via micro-vesicles, secreted and incorporated through a synapse- like mechanism (Albertini et al. 2001; Macaulay et al. 2014, 2016). Through gap-junction mediated-transport, TZPs deliver pyruvate, nicotinamide adenine dinucleotide phosphate (NADPH) and phosporibosyl pyrophosphate (PRPP), which are essential molecules for oocyte ATP production, redox activity and nucleotide synthesis, respectively (Sutton- McDowall et al. 2010). In addition, through gapjunctions, TZPs also transfer cyclic guanosine monophosphate (cGMP) produced by cumulus cells under NPPC stimulation, which maintains the meiotic arrest phase by inhibiting cyclic adenosine monophosphate (CAMP) degradation by phosphodiesterase 3 (PDE3) (Zhang et al. 2010; Conti et al. 2012). In parallel, through the so called gametic synapses, TZPs transfer to the oocyte cumulus-derived poly-A mRNA that are readily incorporated in the translational machinery for the synthesis of important regulators of cytoskeleton and spindle actin dynamics [i.e. Wiscott Aldrich syndrome protein and scar homolog complex family member 2 (WASF2), family with sequence similarity member 21 (FAM21) and paxillin (PXN)] and gene expression (i.e. zinc finger proteins ZFN773, ZNF689, ZNF75A, ZNF664 and ZNF395) (Macaulay et al. 2016). Therefore, while maintaining the meiotic arrest, TZP- mediated cumulusoocyte communication provide resources that are fundamental for the regulation of oocyte metabolism, gene expression, oxidative stress, DNA damage/repair and actin/spindle dynamics, all processes of great relevance for oocyte developmental competence acquisition (J. Buratini, T. T. Dellaqua, M. Dal Canto, A. La Marca, M. Mignini Renzini, R. Webb, unpubl. data).

Interestingly, in addition to gap-junction closure due to connexin phosphorylation (Park et al. 2004), TZP detachment and retraction have been recently suggested to constitute an important mechanism downstream of the LH surge leading to oocyte meiotic resumption through reduced cGMP influx (Abbassi et al. 2021). It is therefore fair to speculate that, in contrast to the ovulatory stage, until the oocyte resources have been sufficiently accumulated to allow precise meiotic completion and hence early embryo development, there might be mechanisms in place aiming to protect TZPs and gap-junctions from eventual precocious threats, being increased FSH activity of special relevance in the context of the present review. Indeed, while increased FSH signalling was shown to decrease TZP density in mice (Combelles et al. 2004) and to compromise gap-junction-mediated cumulus- oocyte communication in cattle (Luciano et al. 2011), preliminary data from our laboratory indicate that oocyte secreted factors (OSF) may decrease FSH responsiveness in cumulus cells (Buratini et al. 2020). Therefore, together with our previous observation that OSFs increase the expression of NPPC in bovine cumulus cells (Lima et al. 2016), these data point to an active participation of the oocyte in the control of its communication with surrounding cumulus cells and of its own differentiation speed, as also suggested by a previous study in mice (Cakmak et al. 2016). The evidencebased molecular paths linking FSH signalling and TZP actin dynamics have been recently revised (J. Buratini, T. T. Dellaqua, M. Dal Canto, A. La Marca, M. Mignini Renzini, R. Webb, unpubl. data).

The hypothesis that increased FSH signalling can com- promise cumulus-oocyte communication and developmental competence is in agreement with several other 
in vivo and in vitro observations. In mice, supplementation of the IVM medium with FSH altered cumulus cell gene expression patterns and reduced embryo production in a dose- dependent manner (Eppig et al. 1998). In cattle, ovarian stimulation with FSH, supposedly leading to increased intrafollicular FSH signalling, advanced germinal vesical breakdown and gap-junction disconnection between the tips of the TZPs and the oocyte (Hyttel et al. 1986, 1991), and reduced oocyte developmental competence as measured by post-IVF blastocyst rates (Blondin et al. 1996). In vitro stimulation of COCs with an elevated concentration of FSH induces an immediate increase in CAMP, accompanied by rapid closure of the gap-junction mediated communications. On the other hand, while there is an immediate drop in intercellular communications in the absence of stimulation, treatments that sustained the intracellular CAMP levels pre- vented the loss of cumulus-oocyte communications (Modina et al. 2001). Subsequent studies have shown that a moderate stimulation through CAMP modulators (Luciano et al. 2004; Thomas et al. 2004) or the administration of approximately physiological concentrations of FSH (Atef et al. 2005; Luciano et al. 2011) can prolong gap-junction mediated communication between the oocyte and surrounding cumulus cells, resulting in a significant increase in oocyte develop- mental competence.

More recently, supraphysiological FSH levels during pre- IVM of growing oocytes were shown to precipitate chromatin compaction in bovine oocytes, which was associated with earlier transcriptional silencing and reduced devel- opmental competence (Luciano et al. 2011). Moreover, in humans, mild ovarian stimulation preceding hCG/GnRH triggering and IVF appears to provide better oocyte quality in comparison with conventional ovarian stimulation with higher FSH doses (Alper and Fauser 2017). Interestingly, mild stimulation has been also associated with lower aneuploidy rates in human IVF (Baart et al. 2007). Considering that aneuploidy is a consequence of meiotic errors and that TZPs deliver cumulus-derived factors that are crucial for spindle actin dynamics control and, therefore, for accurate chromosome segregation (J. Buratini, T. T. Dellaqua, M. Dal Canto, A. La Marca, M. Mignini Renzini, R. Webb, unpubl. data), it is logical to speculate that the causative link between excessive FSH intrafollicular signalling and aneuploidy is the negative impact of FSH on TZP-mediated cumulus-oocyte communication (Combelles et al. 2004). The potential detrimental effects of excessive FSH signalling on oocyte developmental competence reviewed above are illustrated in Fig.1. Despite the evidence above of a negative impact of excessive FSH signalling on oocyte quality, IVM has been predominantly performed in a single culture step with supraphysiological FSH concentrations (Fortune and Hansel 1985; Luciano and Sirard 2018). Recently, nevertheless, new IVM systems comprising two culture steps have been demonstrated to improve oocyte developmental competence in cattle and humans (Albuz et al. 2010; Franciosi et al. 2014; Sánchez et al. 2017; Santiquet et al. 2017). In two-stage IVM, the first culture step, usually designated as pre-IVM, contains either NPPC or a direct PDE3 inhibitor aiming to slow nuclear maturation and prolong cumulus-oocyte communication, while the second culture step contains inducers of the maturation cascade (De Vos et al. 2021). These studies, therefore, support the concept that sudden transfer of the immature oocyte from the follicle to an environment with supraphysiological FSH is detrimental to its developmental competence. It is thus logical to speculate that this sudden environment change as 


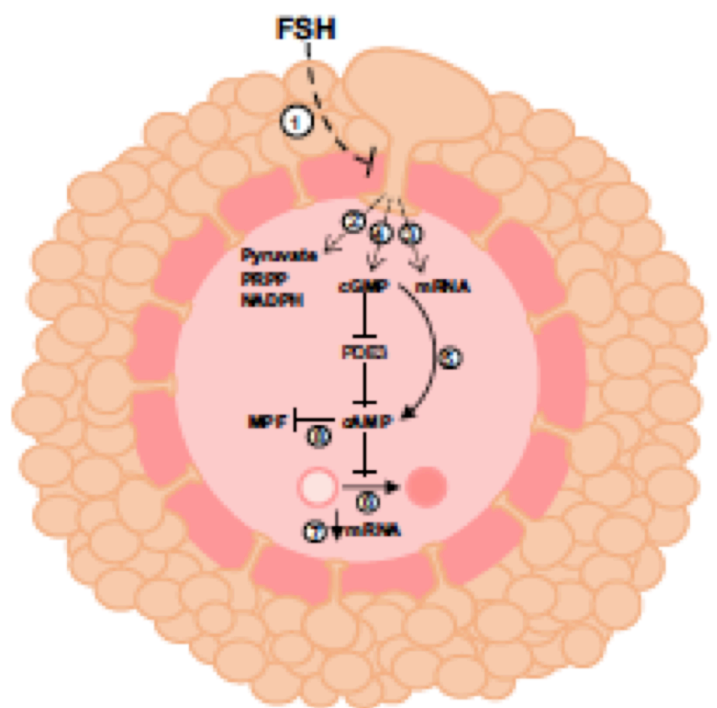

Fig.1. Putative effects of supraphysiological FSH concentrations during IVM on oocyte metabolism and differentiation through TZPmediated cumulus cell-oocyte communication. Excessive FSH signalling decreases cumulusoocyte communication through TZP retraction and gap-junction closure (1). Decreased TZP functionality is accompanied by (2) decreased delivery of pyruvate, PRPP and NADPH, compromising energetic metabolism, nucleotide synthesis and redox activity, as well as (3) of poly-A mRNA regulating cytoskeleton dynamics and gene expression. Decreased TZP functionality also leads to reduced delivery of cumulus cell-derived cGMP (4), which decreases intra-oocyte CAMP levels due to increased PDE3 activity (5). Reduced intra-oocyte cAMP levels prompt premature chromatin compaction (6) in association with transcription silencing (7) and activation of the maturation promoting factor (MPF) cascade leading to meiosis resumption (8).

assess oocyte developmental competence and that synchronising and homogenising the oocyte population before OPU increases the efficiency of IVM.

\section{Chromatin status and oocyte developmental competence}

During the last stages of folliculogenesis, the oocyte acquires developmental competence, which defines the ability of the female gamete to mature into an egg and sustain embryo development to the blastocyst stage after fertilisation (Albertini et al. 2003). Nevertheless, identifying oocytes' developmental competence is extremely complex. The study of large-scale changes in the chromatin configuration has led to identifying a useful marker of development during the different stages of 
oocyte differentiation (De La Fuente 2006; Luciano and Lodde 2013; Luciano et al. 2014).

In cows, four chromatin configurations describe different stages of developmental competence (Lodde et al. 2007). In the GVO configuration, chromatin is mostly uncondensed and dispersed throughout the nucleoplasm, while the appearance of condensation foci signals the transition to the GV1 configuration. Further compaction into distinct aggregates characterises the GV2 configuration, followed by the GV3 as the highest level of compaction, where the chromatin is a single clump in a limited area of the nucleus (Lodde et al. 2007). These GV stages accompany different stages of follicle development. Almost $90 \%$ of the oocytes isolated from early antral follicles ( $\leq 2 \mathrm{~mm}$ in diameter) show a GVO configuration. In contrast, small and medium antral follicles (3-6 $\mathrm{mm}$ in diameter), which are the follicles most used for IVP, do not contain GV0 oocytes, but only GV1, GV2, and GV3 stages in similar proportions (Lodde et al. 2007).

Chromatin configuration is a functional marker of gamete differentiation (Luciano et al. 2014). In bovine oocytes, the transition from GVO to GV3 corresponds to progressive silencing of transcription (Lodde et al. 2008), changes in epigenetic signatures such as global methylation and histone modifications (Labrecque et al. 2015; Lodde et al. 2017), and changes in nuclear architecture and redistribution of cytoplasmic organelles (Lodde et al. 2008). More importantly, the transition from dispersed to compacted chromatin is associated with the gradual acquisition of oocyte meiotic and hence developmental competence (Lodde et al. 2007, 2008; Luciano et al. 2011). Analogous correlations have been described in mice and humans (Zuccotti et al. 1995; Bouniol- Baly et al. 1999; Combelles et al. 2003; Miyara et al. 2003; Sánchez et al. 2015). Noteworthily, changes in chromatin configuration are accompanied by significant modifications in the transcriptome signatures of the oocyte (Labrecque et al. 2015) and corresponding cumulus cells (Dieci et al. 2016), suggesting that chromatin configuration also reflects follicular developmental stage (Luciano and Sirard 2018). Moreover, changes in large-scale chromatin configuration are in close relation with the functional status of gap- junctions through cAMPdependent mechanisms (Luciano et al. 2011; Lodde et al. 2013; Franciosi et al. 2014; Soares et al. 2017). In COCs isolated from early antral follicles, the maintenance of functional gap-junction communications promotes oocyte growth and gradual transcriptional silencing and chromatin remodelling, thus supporting developmental competence acquisition via a cAMP-mediated mechanism (Luciano et al. 2011).

The success in using CAMP modulators in vitro pre-IVM can be affected by the degree of oocyte differentiation. Recent studies in cows showed that pre-IVM might be beneficial for the developmental competence of GV1 oocytes but detrimental for that of GV3 oocytes (Dieci et al. 2016). Oocytes within COCs with a compact cumulus investment and homogeneous ooplasm were found to be less competent than those in which the ooplasm appears granulated and shows slight signs of expansion in the outer layers of the cumulus (Blondin and Sirard 1995). A study conducted in our lab demonstrated that oocytes within COCs with a compact cumulus investment and homogeneous ooplasm tend to display the GV1 chromatin configuration. Alternatively, in COCs exhibiting light expan- sion and granulated cytoplasm, the oocyte chromatin predominantly presented either the GV2 or the GV3 configuration (Dieci et al. 2016). Pre-IVM treatment with a physiological concentration of FSH was 
beneficial to a GV1- enriched oocyte population. In contrast, when standard IVM without pretreatment was applied to this GV1 enriched oocyte population, poor preimplantation embryonic survival was observed. Conversely and strikingly, pre-IVM significantly decreased the blastocyst rate obtained from a GV2-GV3 enriched oocyte population, which, on the other hand, provided better embryo development when directly submitted to the one-step IVM protocol (Dieci et al. 2016).

Pre-IVM protocols substantially improved the devel- opmental competence in other animal models characterised by a more homogeneous population of oocytes. A significant increase in developmental competence was obtained in oocytes with an inherent low embryonic developmental competence, such as prepubertal calves (Donnay et al. 2004) and juvenile mice, using NPPC and lower FSH concentrations closer to physiological levels (Romero et al. 2016). Oocytes isolated from early antral follicles (mostly in the GVO stage), grown in the presence of cilostamide and physiological concentrations of $\mathrm{FSH}$, achieved both meiotic and embryonic developmental competence (Luciano et al. 2011). In the same line, human oocytes aspirated from follicles $<10 \mathrm{~mm}$ of PCOS patients with intrinsically lower developmental potential (Sánchez et al. 2017), or considered to be meiotically incompetent in the face of uncondensed chromatin and degree of cumulus investment expansion (Nogueira et al. 2006; Sánchez et al. 2017), did exhibit chromatin compaction when subjected to pre-IVM (Vanhoutte et al. 2007).

\section{Chromatin configuration as a practical reference for oocyte developmental competence in IVM/IVF}

he comparison between GV patterns observed in oocyte populations yielded by OPU from cattle breeds known to perform differently in IVP illustrates the relevance of chromatin compaction degree for oocyte developmental competence. Oocytes retrieved on a random day of the oestrous cycle from Nelore cows, a Bos indicus breed known to perform better in IVP as compared to Holstein cows (Pontes et al. 2010; Gimenes et al. 2015), were found to predominantly display intermediate or advanced chromatin compaction ( $90 \%$ at GV2 or GV3 stages). Alternatively, in Holstein cows, only $65 \%$ of the oocytes yielded on a random day presented GV2 or GV3 chromatin configuration (Soares et al. 2020b). The higher incidence of GV2 and GV3 oocyte in Nelore as compared to Holstein explains, at least in part, the difference in IVP performances between these breeds, since these chromatin patterns showed higher developmental competence in previous studies with slaughterhouse ovaries (Lodde et al. 2007). It is, nevertheless, essential to point out that Holstein oocytes appear more sensitive to the induction of oocyte maturation in comparison with Nelore. This observation is suggested by faster achievement of germinal vesicle breakdown following removal of the COC from the follicular environment in Holstein (Soares et al. 2017). We, therefore, speculate that GV3 chromatin dynamics and the associated changes in oocytes and cumulus cells may also vary between these breeds. A potentially significant difference between Holstein and Nelore GV3 COCs is the speed at which apoptosis is activated in cumulus cells, a process previously demonstrated to occur during the GV2-GV3 transition (Dieci et al. 2016).

Importantly, our previous observations suggest that, although GV stages may constitute a valuable reference for oocyte developmental competence, there might 
still be vari- ability within GV categories, not only between breeds, but also across different follicular developmental stages. Indeed, the same GV pattern (GV2 and GV3) can be observed in oocytes derived from follicles ranging from $2 \mathrm{~mm}$ to ovulatory diameters (Lodde et al. 2007; Dieci et al. 2016). It is thus logical to expect that the developmental competence of oocytes bearing equivalent chromatin configuration would vary with follicle size (Caixeta et al. 2009). We speculate that devel- opmental competence also depends on the moment at which the oocyte transits to the GV2 and, eventually, to the GV3 stage of chromatin differentiation. Oocytes from follicles that grow in a physiological rhythm, reaching late/preovulatory follicular stages, and transiting gradually through GV1, GV2 and, eventually, GV3 stages, would likely accumulate more transcripts and cumulus cellderived factors to support meiotic completion and hence early embryo development until the maternal-embryonic transition stage, thus achieving superior developmental competence. Further studies are required to better address how developmental competence varies in oocytes morphologically similar and bearing equivalent chromatin configuration. Nevertheless, the speculation above is compatible with previous reports of a higher level of oocyte developmental competence induced with pre-OPU coasting protocols capable of promoting follicle growth up to advanced antral stages (Blondin et al. 2002; Nivet et al. 2012).

Ovarian synchronisation protocols capable to increase the proportion of follicles containing oocytes with a chromatin configuration associated with higher developmental compe- tence would be an interesting alternative to improve IVP efficacy. With this aim, we have developed synchronisation strategies capable of providing GV2 and GV3 enriched oocyte populations in Holstein cows (Soares et al. 2020a, 2020b). An oocyte population with more than $80 \%$ of GV2 oocytes was obtained by combining aspiration of all follicles larger than $3 \mathrm{~mm}$ in diameter on a random day (designated as Day 0), with a mild FSH treatment from Day 2 to Day 3 $(40,40,20$ and 20 mg FSH IM injections on the mornings and evenings of Days 2 and 3, respectively) and OPU on the morning of Day 5 (Soares et al. 2020a). Alternatively, an oocyte population containing around $90 \%$ of GV3 oocytes was obtained associating a slightly different mild stimulation protocol with two $56 \mathrm{mg}$ FSH IM injections $12 \mathrm{~h}$ apart on Day 2, followed by OPU on Day 5 and COC incubation for nine hours in a pre-IVM medium containing NPPC and physiological levels of FSH and steroids (estradiol, progesterone and testosterone). This culture step had been previously demonstrated to delay GVBD and to prolong cumulus-oocyte communication time (Soares et al. 2017). In comparison with a control group without any pre-OPU intervention, the protocol providing a GV2 enriched population of oocytes nearly doubled the blastocyst rate ( $21 \%$ vs $37.9 \%)$ and the production of transferable/freezable blastocysts ( $14.3 \%$ vs $27.7 \%$; 2.8 vs 4.5 embryos per cow, respectively) following IVM/IVF/IVC (Soares et al. 2020a). In contrast, our preliminary results indicate that the protocol providing the GV3 enriched oocyte population do not significantly alter post IVM/IVF/IVC embryo production outcome (Soares et al. 2018).

While indicating that pre-OPU strategies capable of increasing the proportion of GV2 type oocytes can drastically benefit IVP efficacy, the data revisited herein indicate that GV2 oocytes indeed hold higher developmental competence and would, therefore, be expected to be found in growing dominant follicles until ovulation. On 
the other hand, the GV2-GV3 transition would coincide with the onset of atresia, as previously proposed (Luciano and Sirard 2018). Moreover, by suggesting a marked reduction in devel- opmental competence from GV2 to GV3 (Soares et al. 2018, IRRS abstract; Soares et al. 2020a), our data, together with the observation that protocols promoting follicular coasting provide highly competent oocytes (Blondin et al. 2002; Nivet et al. 2012), suggest that the GV3 chromatin pattern is achieved once the process of follicular atresia is already in course. Therefore, it is likely to suggest that, among the population of GV3 oocytes, only those having recently assumed this configuration would hold the desired competence level to be successfully fertilised and to produce a viable (i.e. transferable) embryo. This interesting observation is supported by our personal observation of increased levels of apoptosis in GV3 oocytes (Dieci et al. 2016).

As mentioned above, although chromatin configuration patterns are slightly different in human as compared to bovine oocytes, progressive compaction occurs analogously during follicular development in both species (Miyara et al. 2003). Therefore, despite the intrinsic difficulties in obtaining usable oocyte samples for the establishment of human specific chromatin parameters, GV configuration could serve also as a valuable reference for the optimisation of pre-IVM stimu- latory treatments for women. These parameters would be particularly important to guide the development of 'tailor made' pre-OPU protocols aiming to generate a distinct oocyte population precisely adequate to the culture system. This approach would render the IVP strategy closer to the physiological status, possibly improving IVM/IVF clinical outcomes. Regarding potential short/medium-term positive impacts on human IVF, it could be particularly interesting to develop and test patient typespecific pre-OPU hormonal approaches, aiming to generate distinct oocyte populations predominantly exhibiting low or intermediate degrees of chromatin compaction, to be then matured in vitro with the two step-IVM protocol currently under refinement (Vuong et al. 2020; De Vos et al. 2021).

\section{Conclusions}

In vitro maturation has been applied differently and sub- optimally in ART (i.e. embryo production) applied to cattle and humans. Nevertheless, our increasing knowledge on the physiological regulation of oocyte nuclear maturation has provided valuable parameters for IVM improvement. Data derived from animal models revised herein converge to indicate that the abrupt stimulation of the $\mathrm{COC}$ with supraphys- iological FSH concentrations during IVM may compromise oocyte developmental competence. In addition, the magnitude of this negative impact seems to vary with follicular developmental stage, being oocytes derived from still small- sized/early antral follicles particularly vulnerable due to premature transcriptional silencing and hence interruption of TZP-mediated cumulus-oocyte communication. In parallel, the data integrated herein are also clear in indicating that chromatin configuration serves as a valuable marker of oocyte developmental competence to guarantee accumu- lation of transcripts and cumulus cell-derived factors to support accurate meiotic completion and early embryo development. We foresee that strengthening our knowledge about the regulation of oocyte competence acquisition will support the development of more physiological and efficient IVM/IVF strategies, in which patient (human or bovine)- specific pre-OPU 
approaches providing a homogeneous GV timed oocyte population are matched with specifically in vitro adapted culture systems mimicking the follicular trajectory until the ovulatory stage of development.

\section{Conflicts of interest}

The authors declare that they have no conflicts of interest.

\section{Declaration of funding}

This review was prepared without any specific financial support. 


\section{References}

- Abbassi L, El-Hayek S, Carvalho KF, Wang W, Yang Q, Granados-Aparici S, Mondadori $\mathrm{R}$, Bordignon V, Clarke HJ (2021) Epidermal growth factor receptor signaling uncouples germ cells from the somatic follicular compartment at ovulation. Nature Communications 12, 1438. doi:10.1038/s41467-021-21644-z

- Albertini DF, Combelles CM, Benecchi E, Carabatsos MJ (2001) Cellular basis for paracrine regulation of ovarian follicle development. Reproduction 121(5), 647-653. doi:10.1530/rep.0.1210647

- Albertini DF, Sanfins A, Combelles CMH (2003) Origins and manifestations of oocyte maturation competencies. Reproductive BioMedicine Online 6(4), 410-415. doi:10.1016/S1472-6483(10) 62159-1

- Albuz FK, Sasseville M, Lane M, Armstrong DT, Thompson JG, Gilchrist RB (2010) Simulated physiological oocyte maturation (SPOM): a novel in vitro maturation system that substantially improves embryo yield and pregnancy outcomes. Human Reproduction 25(12), 2999-3011. doi:10.1093/humrep/deq246

- Alper MM, Fauser BC (2017) Ovarian stimulation protocols for IVF: is more better than less? Reproductive BioMedicine Online 34(4), 345-353. doi:10.1016/j.rbmo.2017.01.010

- Atef A, François P, Christian V, Marc-André S (2005) The potential role of gap junction communication between cumulus cells and bovine oocytes during in vitro maturation. Molecular Reproduction and Development 71(3), 358-367. doi:10.1002/mrd.20281

- Baart EB, Martini E, Eijkemans MJ, Van Opstal D, Beckers NGM, Verhoeff A, Macklon NS, Fauser BCJM (2007) Milder ovarian stimulation for in- vitro fertilization reduces aneuploidy in the human preimplantation embryo: a randomized controlled trial. Human Reproduction 22(4), 980-988. doi:10.1093/humrep/del484

- Baruselli PS, Batista EOS, Vieira LM, Ferreira RM, Guerreiro BG, Bayeux BM, Sales JNS, Souza AH, Gimenes LU (2016) Factors that interfere with oocyte quality for in vitro production of cattle embryos: effects of different developmental \& reproductive stages. Animal Reproduction 13(3), 264-272. doi:10.21451/1984-3143AR861

- Blanco MR, Demyda S, Moreno Millán M, Genero E (2011) Developmental competence of in vivo and in vitro matured oocytes: a review. Biotechnology and Molecular Biology Reviews 6(7), 155-165.

- Blondin P, Sirard MA (1995) Oocyte and follicular morphology as determining characteristics for developmental competence in bovine oocytes. Molecular Reproduction and Development 41(1), 54-62. doi:10.1002/mrd.1080410109

- Blondin P, Coenen K, Guilbault LA, Sirard M-A (1996) Superovulation can reduce the developmental competence of bovine embryos. Theriogenology 46(7), 1191-1203. doi:10.1016/S0093-691X(96)

- 00290-7

- Blondin P, Bousquet D, Twagiramungu H, Barnes F, Sirard M-A (2002) Manipulation of follicular development to produce developmentally competent bovine oocytes. Biology of Reproduction 66(1), 38-43. doi:10.1095/biolreprod66.1.38

- Bouniol-Baly C, Hamraoui L, Guibert J, Beaujean N, Szöllösi MS, Debey P (1999) Differential transcriptional activity associated with chromatin configuration in fully grown mouse germinal vesicle oocytes. Biology of Reproduction 60(3), 580-587. doi:10.1095/biolreprod60.3.580

- Buratini J, Soares ACS, Barros RG (2017) Follicular environment and oocyte maturation: roles of local peptides and steroids. Animal Reproduction 14(3), 601606. doi:10.21451/1984-3143-AR1003 
- Buratini J, Dellaqua TT, Dal Canto M, Renzini MM (2020) Oocyte secreted factors regulate FSHR and AMH mRNA levels in cumulus cells. Fertility and Sterility 114(3), e440. doi:10.1016/j.fertnstert.2020.08.1277

- Caixeta ES, Ripamonte P, Franco MM, Junior JB, Dode MAN (2009) Effect of follicle size on mRNA expression in cumulus cells and oocytes of Bos indicus: an approach to identify marker genes for developmental competence. Reproduction, Fertility and Development 21(5), 655-664. doi:10.1071/RD08201

- Cakmak H, Franciosi F, Musa Zamah A, Cedars MI, Conti M (2016) Dynamic secretion during meiotic reentry integrates the function of the oocyte and cumulus cells. Proceedings of the National Academy of Sciences of the United States of America 113(9), 2424-2429. doi:10.1073/pnas.1519990113

- Chen J, Torcia S, Xie F, Lin C-J, Cakmak H, Franciosi F, Horner K, Onodera C, Song JS, Cedars MI, Ramalho-Santos M, Conti M (2013) Somatic cells regulate maternal mRNA translation and developmental competence of mouse oocytes. Nature Cell Biology 15(12), 1415-1423. doi:10.1038/ncb2873

- Combelles CM, Albertini DF, Racowsky C (2003) Distinct microtubule and chromatin characteristics of human oocytes after failed in-vivo and in- vitro meiotic maturation. Human Reproduction 18(10), 2124-2130. doi:10.1093/humrep/deg419

- Combelles CM, Carabatsos MJ, Kumar TR, Matzuk MM, Albertini DF (2004) Hormonal control of somatic cell oocyte interactions during ovarian follicle development. Molecular Reproduction and Development 69(3), 347-355. doi:10.1002/mrd.20128

- Conti M, Hsieh M, Zamah AM, Oh JS (2012) Novel signaling mechanisms in the ovary during oocyte maturation and ovulation. Molecular and Cellular Endocrinology 356(1-2), 65-73. doi:10.1016/j.mce.2011. 11.002

- Coticchio G, Dal Canto M, Fadini R, Mignini Renzini M, Guglielmo MC, Miglietta S, Palmerini MG, Macchiarelli G, Nottola SA (2016) Ultrastructure of human oocytes after in vitro maturation. Molecular Human Reproduction 22(2), 110-118. doi:10.1093/molehr/gav071

- Dal Canto M, Coticchio G, Mignini Renzini M, De Ponti E, Novara PV, Brambillasca F, Comi R, Fadini R (2012) Cleavage kinetics analysis of human embryos predicts development to blastocyst and implantation. Reproductive BioMedicine Online 25(5), 474-480. doi:10.1016/j.rbmo. 2012.07.016

- De La Fuente R (2006) Chromatin modifications in the germinal vesicle (GV) of mammalian oocytes. Developmental Biology 292(1), 1-12. doi:10.1016/j.ydbio.2006.01.008

- De Vos M, Smitz J, Thompson JG, Gilchrist RB (2016) The definition of IVM is clearvariations need defining. Human Reproduction 31(11), 2411-2415. doi:10.1093/humrep/dew208

- De Vos M, Grynberg M, Ho TM, Yuan Y, Albertini DF, Gilchrist RB (2021) Perspectives on the development and future of oocyte IVM in clinical practice. Journal of Assisted Reproduction and Genetics 38(6), 1265-1280. doi:10.1007/s10815-021-02263-5

- Dieci C, Lodde V, Labreque R, Dufort I, Tessaro I, Sirard MA, Luciano AM (2016) Differences in cumulus cell gene expression indicate the benefit of a pre-maturation step to improve in-vitro bovine embryo production. Molecular Human Reproduction 22(12), 882-897

- Donnay I, Faerge I, Grøndahl C, Verhaeghe B, Sayoud H, Ponderato N, Galli C, Lazzari $G$ (2004) Effect of prematuration, meiosis activating sterol and enriched maturation medium on the nuclear maturation and competence to development of calf oocytes. Theriogenology 62(6), 1093-1107. doi:10.1016/j.theriogenology.2003.12.019 
- Eppig JJ, O'Brien MJ, Pendola FL, Watanabe S (1998) Factors affecting the developmental competence of mouse oocytes grown in vitro: follicle-stimulating hormone and insulin. Biology of Reproduction

- 59(6), 1445-1453. doi:10.1095/biolreprod59.6.1445

- Fadini R, Dal Canto MB, Renzini MM, Brambillasca F, Comi R, Fumagalli D, Lain M, Merola M, Milani R, De Ponti E (2009) Effect of different gonadotrophin priming on IVM of oocytes from women with normal ovaries: a prospective randomized study. Reproductive BioMedicine Online 19(3), 343-351. doi:10.1016/S1472-6483(10)

- 60168-X

- Fadini R, Mignini Renzini M, Dal Canto M, Epis A, Crippa M, Caliari I, Brigante C, Coticchio $G$ (2013) Oocyte in vitro maturation in normo-ovulatory women. Fertility and Sterility 99(5), 1162-1169. doi:10.1016/j.fertnstert.2013.01.138

- Fadini R, Coticchio G, Brambillasca F, Mignini Renzini M, Novara PV, Brigante C, De Ponti E, Dal Canto M (2015) Clinical outcomes from mature oocytes derived from preovulatory and antral follicles: reflections on follicle physiology and oocyte competence. Journal of Assisted Reproduction and Genetics 32(2), 255-261. doi:10.1007/ s10815-014-0386-x

- Fortune JE, Hansel W (1985) Concentrations of steroids and gonadotropins in follicular fluid from normal heifers and heifers primed for superovulation. Biology of Reproduction 32(5), 1069-1079. doi:10.1095/biolreprod32.5.1069

- Franciosi F, Coticchio G, Lodde V, Tessaro I, Modina SC, Fadini R, Dal Canto M, Renzini MM, Albertini DF, Luciano AM (2014) Natriuretic peptide precursor C delays meiotic resumption and sustains gap junction-mediated communication in bovine cumulus-enclosed oocytes. Biology of Reproduction 91(3), 61. doi:10.1095/biolreprod. 114.118869

- Gilchrist RB (2011) Recent insights into oocyte-follicle cell interactions provide opportunities for the development of new approaches to in vitro maturation. Reproduction, Fertility and Development 23, 23-31. doi:10.1071/RD10225

- Gimenes LU, Ferraz ML, Fantinato-Neto P, Chiaratti MR, Mesquita LG, Sá Filho MF, Meirelles FV, Trinca LA, Renno' FP, Watanabe YF, Baruselli PS (2015) The interval between the emergence of pharmacologically synchronized ovarian follicular waves and ovum pickup does not significantly affect in vitro embryo production in Bos indicus, Bos taurus, and Bubalus bubalis. Theriogenology 83(3), 385-393. doi:10.1016/j.theriogenology.2014.09.030

- Hyttel P (1987) Bovine cumulus-oocyte disconnection in vitro. Anatomy and Embryology 176(1), 41-44. doi:10.1007/BF00309750

- Hyttel P, Callesen H, Greve T (1986) Ultrastructural features of preovulatory oocyte maturation in superovulated cattle. Reproduction 76(2), 645-656. doi:10.1530/jrf.0.0760645

- Hyttel P, Callesen H, Greve T, Schmidt M (1991) Oocyte maturation and sperm transport in superovulated cattle. Theriogenology 35(1), 91-108. doi:10.1016/0093$691 \times(91) 90150-C$

- Jie H, Zhao M, Alqawasmeh OAM, Chan CPS, Lee TL, Li T, Chan DYL (2021) In vitro rescue immature oocytes - a literature review. Human Fertility 137, 1-20. doi:10.1080/14647273.2021.1876932

- Katz-Jaffe MG, McCallie BR, Preis KA, Filipovits J, Gardner DK (2009) Transcriptome analysis of in vivo and in vitro matured bovine MII oocytes. Theriogenology 71(6), 939-946. doi:10.1016/j.theriogenology. 2008.10.024

- Labrecque R, Lodde V, Dieci C, Tessaro I, Luciano AM, Sirard MA (2015) Chromatin remodelling and histone $m$ RNA accumulation in bovine germinal vesicle oocytes. Molecular Reproduction and Development 82(6), 450-462. doi:10.1002/mrd.22494 
- Lima PF, Ormond CM, Caixeta ES, Barros RG, Price CA, Buratini J (2016) Effect of kit ligand on natriuretic peptide precursor $C$ and oocyte maturation in cattle. Reproduction 152(5), 481-489. doi:10.1530/ REP-16-0155

- Lodde V, Modina S, Galbusera C, Franciosi F, Luciano AM (2007) Large- scale chromatin remodeling in germinal vesicle bovine oocytes: interplay with gap junction functionality and developmental competence. Molecular Reproduction and Development 74(6), 740-749

- Lodde V, Modina S, Maddox-Hyttel P, Franciosi F, Lauria A, Luciano AM (2008) Oocyte morphology and transcriptional silencing in relation to chromatin remodeling during the final phases of bovine oocyte growth. Molecular Reproduction and Development 75(5), 915-924. doi:10.1002/mrd.20824

- Lodde V, Franciosi F, Tessaro I, Modina SC, Luciano AM (2013) Role of gap junctionmediated communications in regulating large-scale chromatin configuration remodeling and embryonic developmental competence acquisition in fully grown bovine oocyte. Journal of Assisted Reproduction and Genetics 30(9), 1219-1226. doi:10.1007/ s10815-013-0061-7

- Luciano AM, Lodde V (2013) Changes of large-scale chromatin configuration during mammalian oocyte differentiation. In 'Oogenesis'. (Eds G Coticchio, D Albertini, L De Santis) pp. 93-108. (Springer: London, UK) doi:10.1007/978-0-85729-826-3_7

- Luciano AM, Sirard MA (2018) Successful in vitro maturation of oocytes: a matter of follicular differentiation. Biology of Reproduction 98(2), 162-169. doi:10.1093/biolre/iox149

- Luciano AM, Modina S, Vassena R, Milanesi E, Lauria A, Gandolfi F (2004) Role of intracellular cyclic adenosine 30,50 -monophosphate concentration and oocytecumulus cells communications on the acquisition of the developmental competence during in vitro maturation of bovine oocyte. Biology of Reproduction 70(2), 465472. doi:10.1095/biolreprod.103.020644

- Luciano AM, Franciosi F, Modina SC, Lodde V (2011) Gap junction- mediated communications regulate chromatin remodeling during bovine oocyte growth and differentiation through cAMP-dependent mechanism(s). Biology of Reproduction 85(6), 1252-1259. doi:10.1095/biolreprod.111.092858

- Luciano AM, Franciosi F, Dieci C, Lodde V (2014) Changes in large-scale chromatin structure and function during oogenesis: a journey in company with follicular cells. Animal Reproduction Science 149(1-2), 3-10. doi:10.1016/j.anireprosci.2014.06.026

- Lodde V, Luciano AM, Franciosi F, Labrecque R, Sirard MA (2017) Accumulation of chromatin remodelling enzyme and histone transcripts in bovine oocytes. In 'Oocytes. Results and problems in cell differentiation'. Vol. 63. (Ed. M Kloc) pp. 223255. (Springer: Cham, Switzerland) doi:10.1007/978-3-319-60855-6_11

- Macaulay AD, Gilbert I, Caballero J, Barreto R, Fournier E, Tossou P, Sirard MA, Clarke HJ, Khandjian EW, Richard FJ, Hyttel P, Robert C (2014) The gametic synapse: RNA transfer to the bovine oocyte. Biology of Reproduction 91(4), 90. doi:10.1095/biolreprod.114. 119867

- Macaulay AD, Gilbert I, Scantland S, Fournier E, Ashkar F, Bastien A, Saadi HA, Gagné D, Sirard MA, Khandjian EW, Richard FJ, Hyttel P, Robert C (2016) Cumulus cell transcripts transit to the bovine oocyte in preparation for maturation. Biology of Reproduction 94(1), 16. doi:10.1095/biolreprod.114.127571

- Miyara F, Migne C, Dumont-Hassan M, Le Meur A, Cohen-Bacrie P, Aubriot FX, Glissant A, Nathan C, Douard S, Stanovici A, Debey P (2003) Chromatin configuration and transcriptional control in human and mouse oocytes. Molecular Reproduction and Development 64(4), 458-470. doi:10.1002/mrd.10233 
- Modina S, Luciano AM, Vassena R, Baraldi-Scesi L, Lauria A, Gandolfi F (2001) Oocyte developmental competence after in vitro maturation depends on the persistence of cumulus-oocyte communications which are linked to the intracellular concentration of cAMP. Journal of Anatomy and Embryology 106(2 Suppl 2), 241-248.

- Nivet AL, Bunel A, Labrecque R, Belanger J, Vigneault C, Blondin P, Sirard MA (2012) FSH withdrawal improves developmental competence of oocytes in the bovine model. Reproduction 143(2), 165-171. doi:10.1530/REP-11-0391

- Nogueira D, Ron-El R, Friedler S, Schachter M, Raziel A, Cortvrindt R, Smitz J (2006) Meiotic arrest in vitro by phosphodiesterase 3-inhibitor enhances maturation capacity of human oocytes and allows subsequent embryonic development. Biology of Reproduction 74(1), 177-184. doi:10.1095/biolreprod.105.040485

- Park JY, Su YQ, Ariga M, Law E, Jin SLC, Conti M (2004) EGF-like growth factors as mediators of LH action in the ovulatory follicle. Science 303(5658), 682-684. doi:10.1126/science.1092463

- Pontes JHF, Silva KCF, Basso AC, Rigo AG, Ferreira CR, Santos GMG, Sanches BV, Porcionato JPF, Vieira PHS, Faifer FS, Sterza FAM, Schenk JL, Seneda MM (2010) Large-scale in vitro embryo production and pregnancy rates from Bos taurus, Bos indicus, and indicus-taurus dairy cows using sexed sperm. Theriogenology 74(8), 1349-1355. doi:10.1016/j.theriogenology.2010.06.004

- Richani D, Dunning KR, Thompson JG, Gilchrist RB (2021) Metabolic co-dependence of the oocyte and cumulus cells: essential role in determining oocyte developmental competence. Human Reproduction Update 27(1), 27-47. doi:10.1093/humupd/dmaa043 Rizos D, Ward F, Duffy PAT, Boland MP, Lonergan P (2002) Consequences of bovine oocyte maturation, fertilization or early embryo development in vitro versus in vivo: implications for blastocyst yield and blastocyst quality. Molecular Reproduction and Development 61(2), 234-248. doi:10.1002/mrd.1153

- Romero S, Sánchez F, Lolicato F, Van Ranst H, Smitz J (2016) Immature oocytes from unprimed juvenile mice become a valuable source for embryo production when using C-type natriuretic peptide as essential component of culture medium. Biology of Reproduction 95(3), 64. doi:10.1095/biolreprod.116.139808

- Russell DL, Gilchrist RB, Brown HM, Thompson JG (2016) Bidirectional communication between cumulus cells and the oocyte: old hands and new players? Theriogenology 86(1), 62-68. doi:10.1016/ j.theriogenology.2016.04.019

- Sánchez F, Romero S, De Vos M, Verheyen G, Smitz J (2015) Human cumulusenclosed germinal vesicle oocytes from early antral follicles reveal heterogeneous cellular and molecular features associated with in vitro maturation capacity. Human Reproduction 30(6), 1396-1409. doi:10.1093/humrep/dev083

- Sánchez F, Lolicato F, Romero S, De Vos M, Van Ranst H, Verheyen G, Anckaert E, Smitz JEJ (2017) An improved IVM method for cumulus-oocyte complexes from small follicles in polycystic ovary syndrome patients enhances oocyte competence and embryo yield. Human Reproduction 32(10), 2056-2068. doi:10.1093/humrep/ dex262

- Sanchez F, Le AH, Ho VNA, Romero S, Van Ranst H, De Vos M, Gilchrist RB, Ho TM, Vuong LN, Smitz J (2019) Biphasic in vitro maturation (CAPA-IVM) specifically improves the developmental capacity of oocytes from small antral follicles. Journal of Assisted Reproduction and Genetics 36(10), 2135-2144. doi:10.1007/s10815-01901551-5

- Santiquet NW, Greene AF, Becker J, Barfield JP, Schoolcraft WB, Krisher RL (2017) A pre-in vitro maturation medium containing cumulus oocyte complex ligand-receptor signaling molecules maintains meiotic arrest, supports the cumulus oocyte complex 
and improves oocyte developmental competence. Molecular Human Reproduction 23(9), 594-606. doi:10.1093/molehr/gax032

- Sirard MA (2016) Somatic environment and germinal differentiation in antral follicle: the effect of FSH withdrawal and basal LH on oocyte competence acquisition in cattle. Theriogenology 86(1), 54-61. doi:10.1016/j.theriogenology.2016.04.018

- Sirard MA, Richard F, Blondin P, Robert C (2006) Contribution of the oocyte to embryo quality. Theriogenology 65(1), 126-136. doi:10.1016/j.theriogenology.2005.09.020

- Soares ACS, Lodde V, Barros RG, Price CA, Luciano AM, Buratini J (2017) Steroid hormones interact with natriuretic peptide $C$ to delay nuclear maturation, to maintain oocyte-cumulus communication and to improve the quality of in vitroproduced embryos in cattle. Reproduction, Fertility and Development 29(11), 22172224. doi:10.1071/RD16320

- Soares A, Lodde V, Bragança L, Marques K, Luciano A, Buratini J (2018) Effects of ovarian synchronization associated with a two-step IVM strategy on in vitro embryo production in cattle. In 'IRRS international uminant reproduction symposium', 16-20 September 2018.

- pp. 1152-1152. (Animal Reproduction: Foz do Iguau, Brazil)

- Soares ACS, Marques KNG, Bragança LGM, Lodde V, Luciano AM, Buratini J (2020a) Synchronization of germinal vesicle maturity improves efficacy of in vitro embryo production in Holstein cows. Theriogenology 154, 53-58. doi:10.1016/j.theriogenology.2020.

- 05.030

- Soares ACS, Sakoda JN, Gama IL, Bayeux BM, Lodde V, Luciano AM, Buratini J (2020b) Characterization and control of oocyte large-scale chromatin configuration in different cattle breeds. Theriogenology 141, 146-152. doi:10.1016/j.theriogenology.2019.09.020

- Sutton ML, Gilchrist RB, Thompson JG (2003) Effects of in-vivo and in-vitro environments on the metabolism of the cumulus-oocyte complex and its influence on oocyte developmental capacity. Human Reproduction Update 9(1), 35-48. doi:10.1093/humupd/ dmg009

- Sutton-McDowall ML, Gilchrist RB, Thompson JG (2010) The pivotal role of glucose metabolism in determining oocyte developmental competence. Reproduction 139(4), 685-695. doi:10.1530/REP-09- 0345

- Thomas RE, Thompson JG, Armstrong DT, Gilchrist RB (2004) Effect of specific phosphodiesterase isoenzyme inhibitors during in vitro maturation of bovine oocytes on meiotic and developmental capacity. Biology of Reproduction 71(4), 1142-1149. doi:10.1095/ biolreprod.103.024828

- Vanhoutte L, De Sutter P, Nogueira D, Gerris J, Dhont M, Van der Elst J (2007) Nuclear and cytoplasmic maturation of in vitro matured human oocytes after temporary nuclear arrest by phosphodiesterase 3-inhibitor. Human Reproduction 22(5), 1239-1246. doi:10.1093/ humrep/dem007

- Viana J (2020) 2019 Statistics of embryo production and transfer in domestic farm animals. Embryo Technology Newsletter 38(4).

- Vuong LN, Le AH, Ho VNA, Pham TD, Sanchez F, Romero S, De Vos M, Ho TM, Gilchrist RB, Smitz J (2020) Live births after oocyte in vitro maturation with a prematuration step in women with polycystic ovary syndrome. Journal of Assisted Reproduction and Genetics 37(2), 347-357. doi:10.1007/s10815-019-01677-6

- Webb R, Buratini J (2016) Global challenges for the 21st century: the role and strategy of the agri-food sector. Animal Reproduction 13(3), 133-142. doi:10.21451/1984-3143-AR882 
- Zhang M, Su Y-Q, Sugiura K, Xia G, Eppig JJ (2010) Granulosa cell ligand NPPC and its receptor NPR2 maintain meiotic arrest in mouse oocytes. Science 330(6002), 366369. doi:10.1126/science.1193573

- Zhang M, Su Y-Q, Sugiura K, Wigglesworth K, Xia G, Eppig JJ (2011) Estradiol promotes and maintains cumulus cell expression of natriuretic peptide receptor 2 (NPR2) and meiotic arrest in mouse oocytes in vitro. Endocrinology 152(11), 43774385. doi:10.1210/ en.2011-1118

- Zuccotti M, Piccinelli A, Rossi PG, Garagna S, Redi CA (1995) Chromatin organization during mouse oocyte growth. Molecular Reproduction and Development 41(4), 479485. doi:10.1002/mrd.1080410410 